\title{
White and red blood cell picture in rabbits experimentally infected with strains of the rabbit haemorrhagic disease (RHD) virus without or with variable haemagglutination capacity
}

\author{
P. Niedźwiedzka-Rystwej ${ }^{1}$, B. Tokarz-Deptuła ${ }^{1}$, W. Deptuła ${ }^{2}$ \\ ${ }^{1}$ Department of Immunology, Faculty of Biology, \\ University of Szczecin, Felczaka 3c, 71-412 Szczecin, Poland \\ ${ }^{2}$ Department of Microbiology, Faculty of Biology, \\ University of Szczecin Felczaka 3c, 71-412 Szczecin, Poland
}

\begin{abstract}
The aim of the study was to establish if haemagglutination of rabbit haemorrhagic disease virus (RHDV) affects haematological picture of peripheral blood in rabbits and the pathogenicity of the virus. The study analyzed white and red blood cell picture in rabbits experimentally infected with two non-haemagglutinating (HA-) RHDV strains (Frankfurt and Asturias) and one strain with variable haemagglutination capacity $(\mathrm{HA}+/-)$ (Hagenow). Studies with HA- and $\mathrm{HA}+/$ - are rare and relate only to 4 HA- strains (2 RHDV: BLA and Rainham; 2 RHDVa: Pv97 and 9905) and 1 HA+/- RHDV strain: ŻD, where less changes in haematological indices and less pathogenicity were observed. We found that changes caused by HA- Frankfurt strain were related to the number of neutrophils and thrombocytes, while in HA- strain Asturias, in thrombocytes and leukocytes. Changes evoked by $\mathrm{HA}+/$ - Hagenow strain pertained to the number of eosinophils, thrombocytes, leukocytes, monocytes, and concentration of hemoglobin. Mortality caused by the Frankfurt strain was $100 \%$ between 36 and $48 \mathrm{~h}$ post infection (p.i.), while that caused by Asturias strain was $100 \%$ between 24 and 36 h p.i., and that observed in case of Hagenow strain was $90 \%$ between 36 and 48 h p.i. The changes in haematological picture caused by the HA- and HA+/- RHDV strains were less intensive than those found in case of the HA+ RHDV strains, which cannot be confirmed for pathogenicity, and is not in line with the existing hypothesis suggesting higher pathogenicity in HA+ viruses.
\end{abstract}

Key words: rabbit haemorrhagic disease virus, haemagglutination, haematology 


\section{Introduction}

In the assessment of the organism's health, hematological factors in infections play a major role. As indicated by the studies on the rabbit haemorrhagic disease virus (RHDV), the analysis of haematological factors, including the immunological picture, is an important element in assessing the physiological condition in animals infected with this virus (Piekarski 1994, Deptuła et al. 1997, Tokarz-Deptuła 1998, Hukowska-Szematowicz 2006, Niedźwiedzka 2008, Niedźwiedzka-Rystwej and Deptuła 2009, 2011a,b, Tokarz-Deptuła 2009). Haematological analyzes in rabbits infected with RHDV carried out by authors from outside Poland (Table 1) regarding 9 different exclusively haemagglutinating $(\mathrm{HA}+)$ virus strains showed a decrease in values of haematological factors dealing with the total number of leukocytes, lymphocytes, and thrombocytes. Polish studies involving $21 \mathrm{HA}+$ (Table 2) RHDV strains including RHDVa, obtained from various European countries, evidenced that the infection causes changes in haematological parameters for $\mathrm{HA}+$ RHDV strains (Table 2, 2a), represented by both a decrease and increase in the values, although there were more decreases referring mainly to the number of lymphocytes as well as quantities of leukocytes and neutrophils. The same Polish studies involving 4 non-haemagglutinating (HA-) strains (two RHDV and RHDVa) and one RHDV strain with variable haemagglutinating $(\mathrm{HA}+/-)$ (Table $2,2 \mathrm{a})$ revealed fewer changes in haematological factors in $\mathrm{HA}+$ RHDV strains, yet they were also more frequently manifested with a decrease in the values referring to thrombocytes, leukocytes, lymphocytes, neutrophils, and haemoglobin concentration. The study results proved that the animal mortality after the infection with 16 HA+ RHDV and RHDVa strains, four HAstrains, and one $\mathrm{HA}+/-$ strain of the RHD virus (Table 1, 2, 2a) is similar, as in the majority of both RHDV and RHDVa strains, mortality ranged from $80 \%$ to $100 \%$, while very rarely below $50 \%$, whereas deaths most frequently occurred between 48 and 60 $\mathrm{h}$ after rabbit infection with the virus. In clinical sciences, however, it is assumed that haemagglutination capacity of viruses is a decisive element for their pathogenicity (Ruvoén-Clouet et al. 2000), which was also confirmed for RHDV by Capucci et al. (1998); hence, it was assumed that HA+ RHDV strains should cause greater changes in the haematological picture than HA- strains as a result of the macro-organism's response to more pathogenic agents.

In addition, RHDV's haemagglutination capacity is a specific feature of the virus, and its absence is very rare, recorded just in 7 out of approximately 500
RHDV strains known worldwide. The feature is absent in English Rainham strain described in 1993 (Capucci et al. 1996), Polish Blaszki (BLA) recorded in 1994 (Kęsy et al. 1996), German Frankfurt (Fra) (Schirrmeier et al. 1999), and Spanish Asturias strains isolated in 1996 (Prieto et al. 2000), as well as in three Chinese strains (whn-1, whn-2, and whn-3) reported in 2005 (Tian et al. 2007). Moreover, within RHDVa, French 9905 (Le Gall Recule 2003) and Italian Pv97 (Capucci et al. 1998) strains were recorded as non-haemagglutinating. RHDV strains exhibit variable haemagglutination capacity - German Hagenow strain described in 1990 (Schirrmeier et al. 1999), Italian Bg97 from 1997 (Capucci et al. 1998), and Polish $\dot{Z} D$ strain isolated in 2000 (Fitzner 2006). Also among RHDV2 strains, which can infect not only rabbits but also hares (Le Gall Recule 2013), strain N11 was recorded, which shows a negative capacity for blood groups $\mathrm{O}$ and $\mathrm{A}$ while positive for blood groups $B$ and AB (Dalton et al. 2012).

Because previous studies analyzing haematological factors in rabbits infected with non-haemagglutinating (HA-) strains of RHDV and strains revealing variable haemagglutination capacity $(\mathrm{HA}+/-)$, involving just two HA- strains (BLA and Rainham) and one $\mathrm{HA}+/-$ strain $(\dot{\mathrm{Z} D})$, the research was performed to extend the data referring to the white and red blood cell picture of peripheral blood in rabbits infected with other two HA- RHDV strains (Frankfurt and Asturias) and one $\mathrm{HA}+/-$ strain (Hagenow), which (together with recorded mortality rate) should provide the answer whether RHDV haemagglutination capacity affects the haematological picture of peripheral blood and conditions its pathogenicity.

\section{Materials and Methods}

The studies involved 60 mixed-race rabbits of both sexes weighing from 3.2 to $4.2 \mathrm{~kg}$. The animals originated from a licensed farm, and remained under continuous veterinary-zootechnical supervision (Anon 1987). During the experiment, the animals stayed at the vivarium of the Department of Microbiology and Department of Immunology, Faculty of Biology, University of Szczecin, where zootechnical parameters were conformant to the standards recommended in Poland in respect of temperature, ventilation, lighting, and size of cages for animals (Anon 2010). After transporting to the vivarium, the animals were subjected to a two-week adaptation period and were fed with full-portion rabbit feed (16\% Królik z Motycza), ranging in the quantity of $0.15-0.20 \mathrm{~kg} /$ day and had unlimited access to water. The studies were accepted 


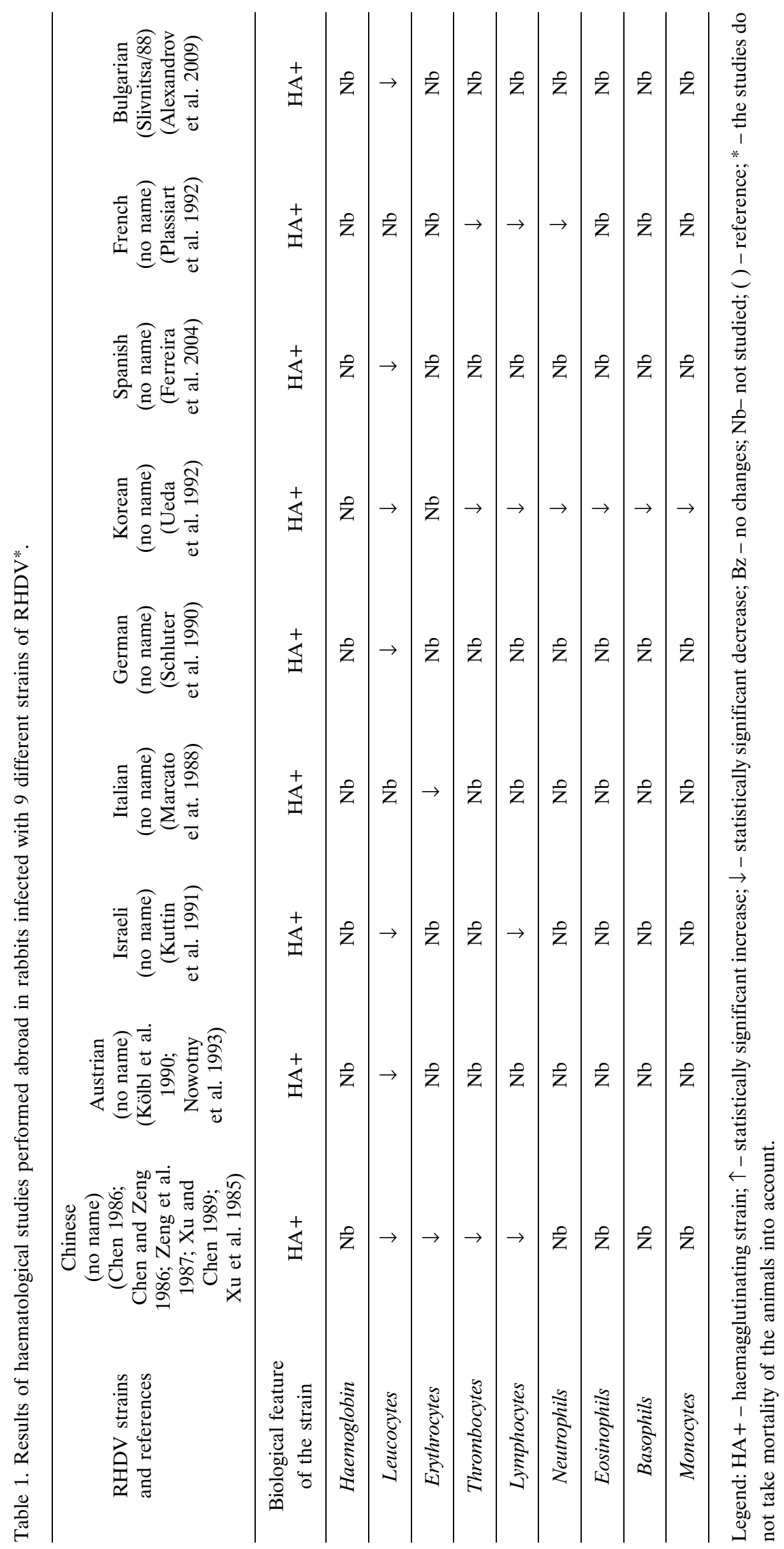




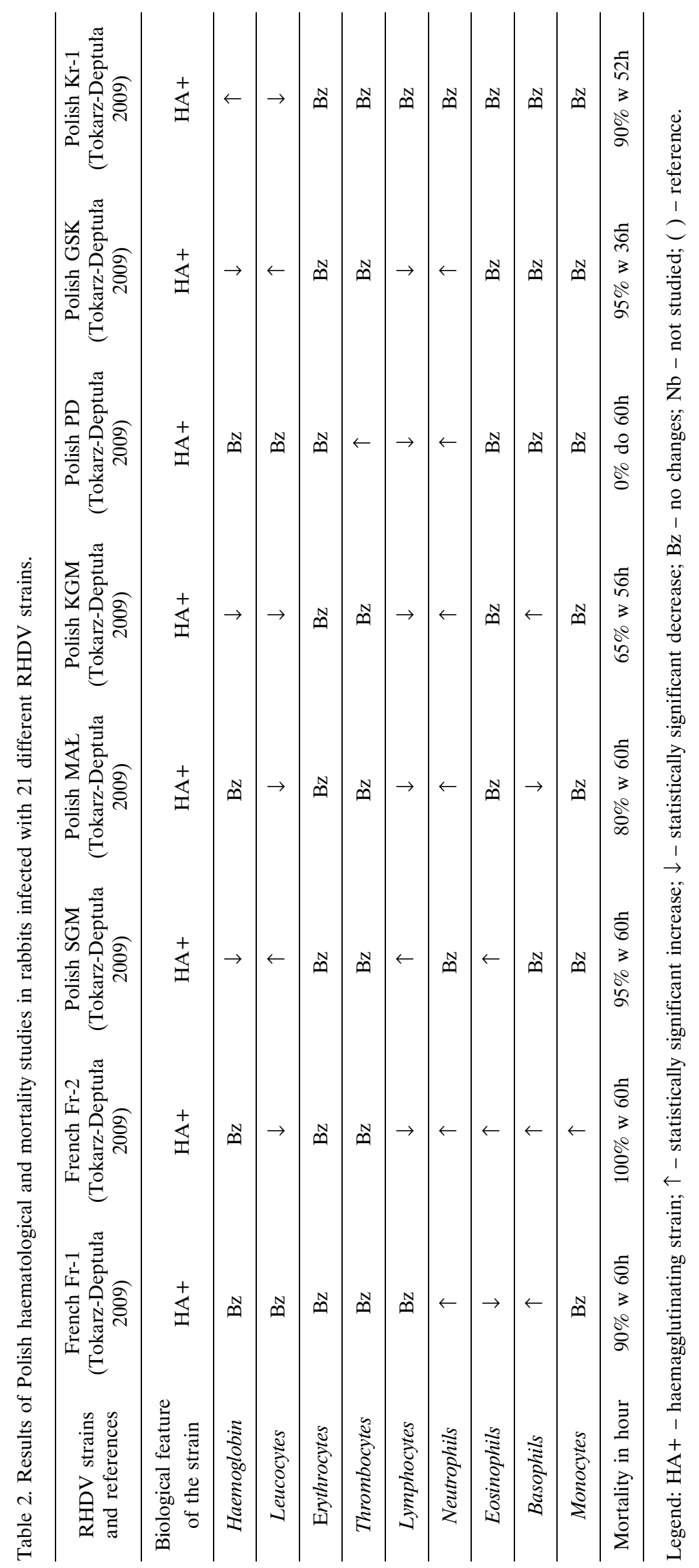




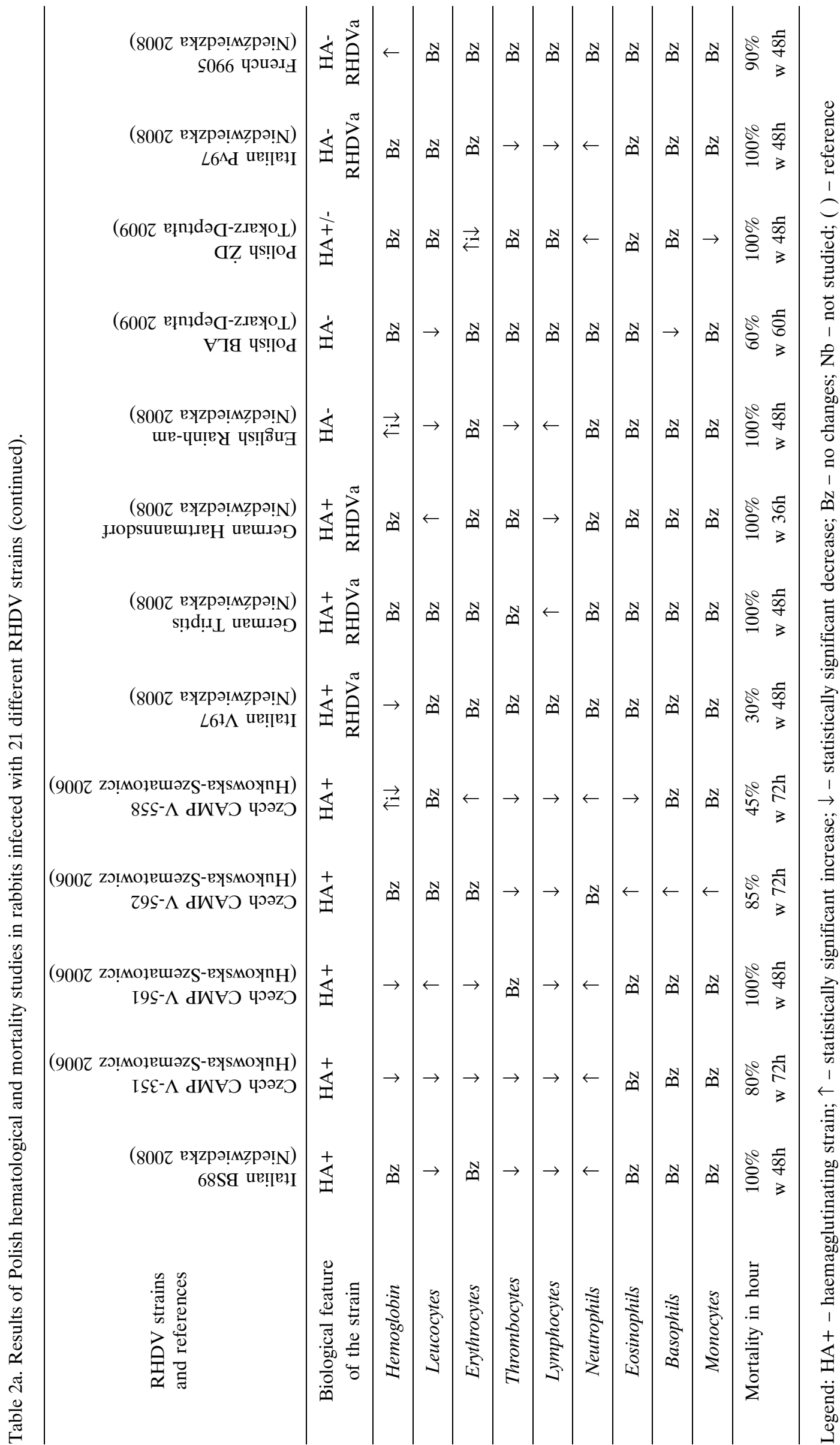




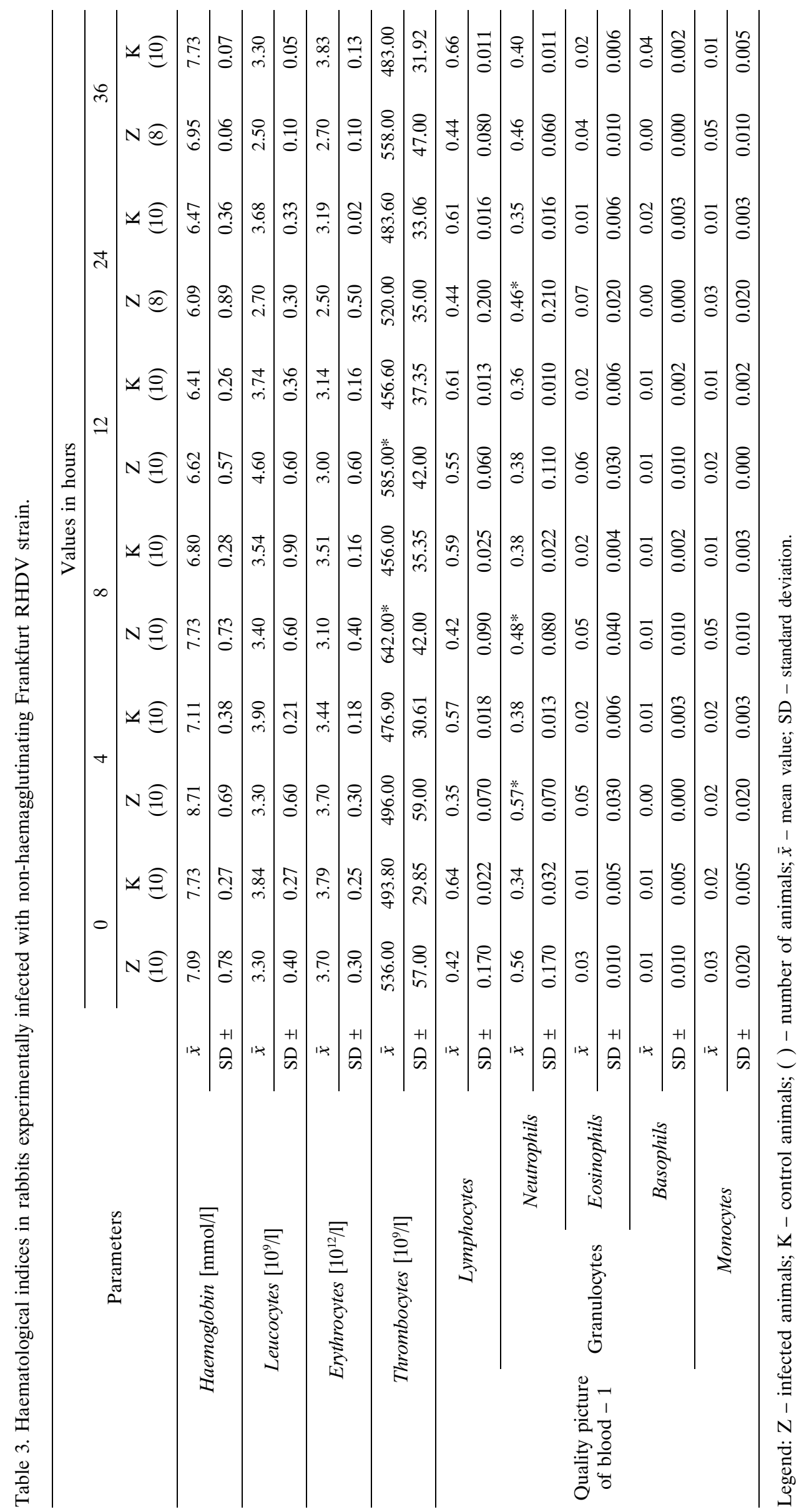




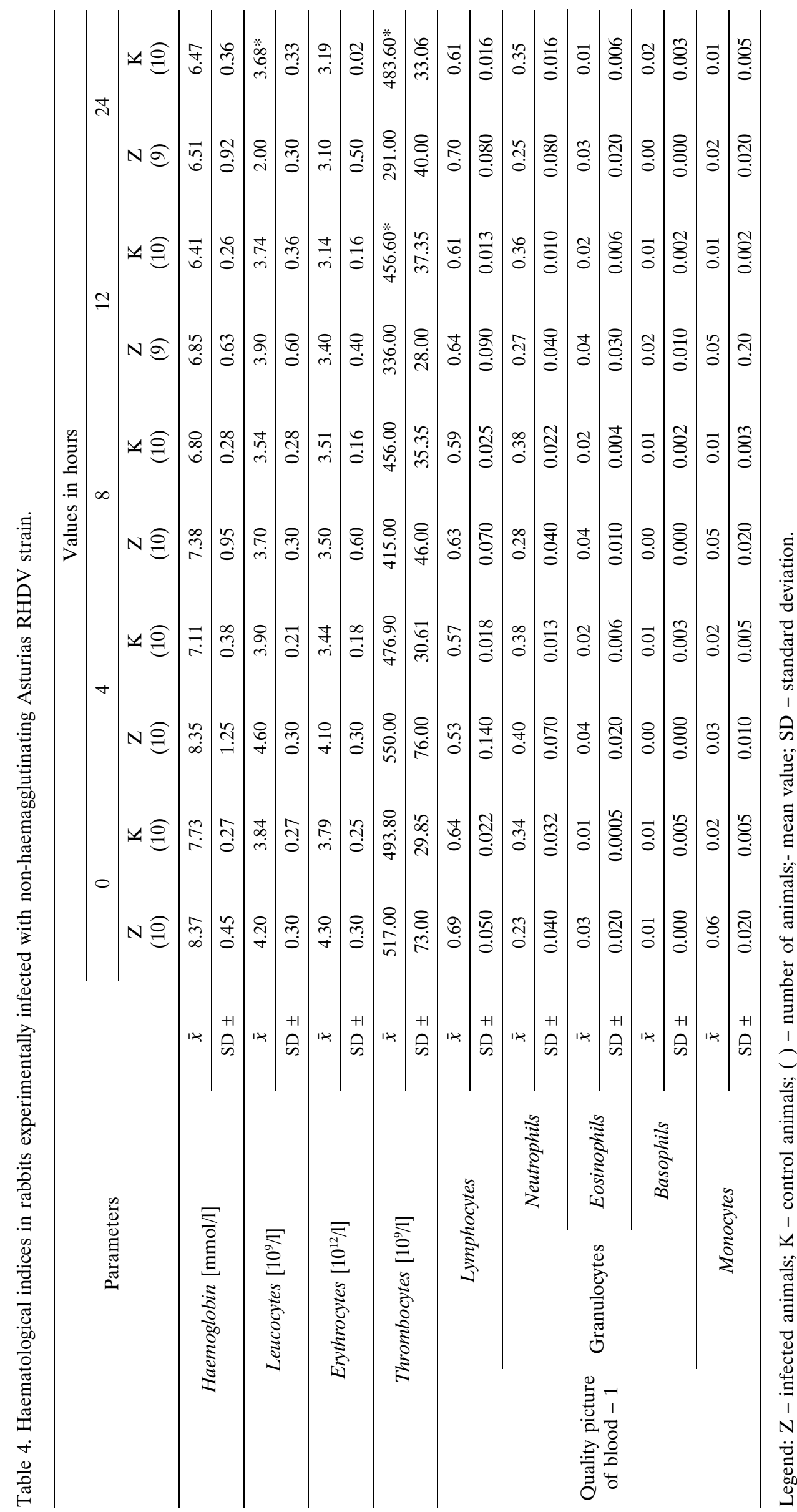




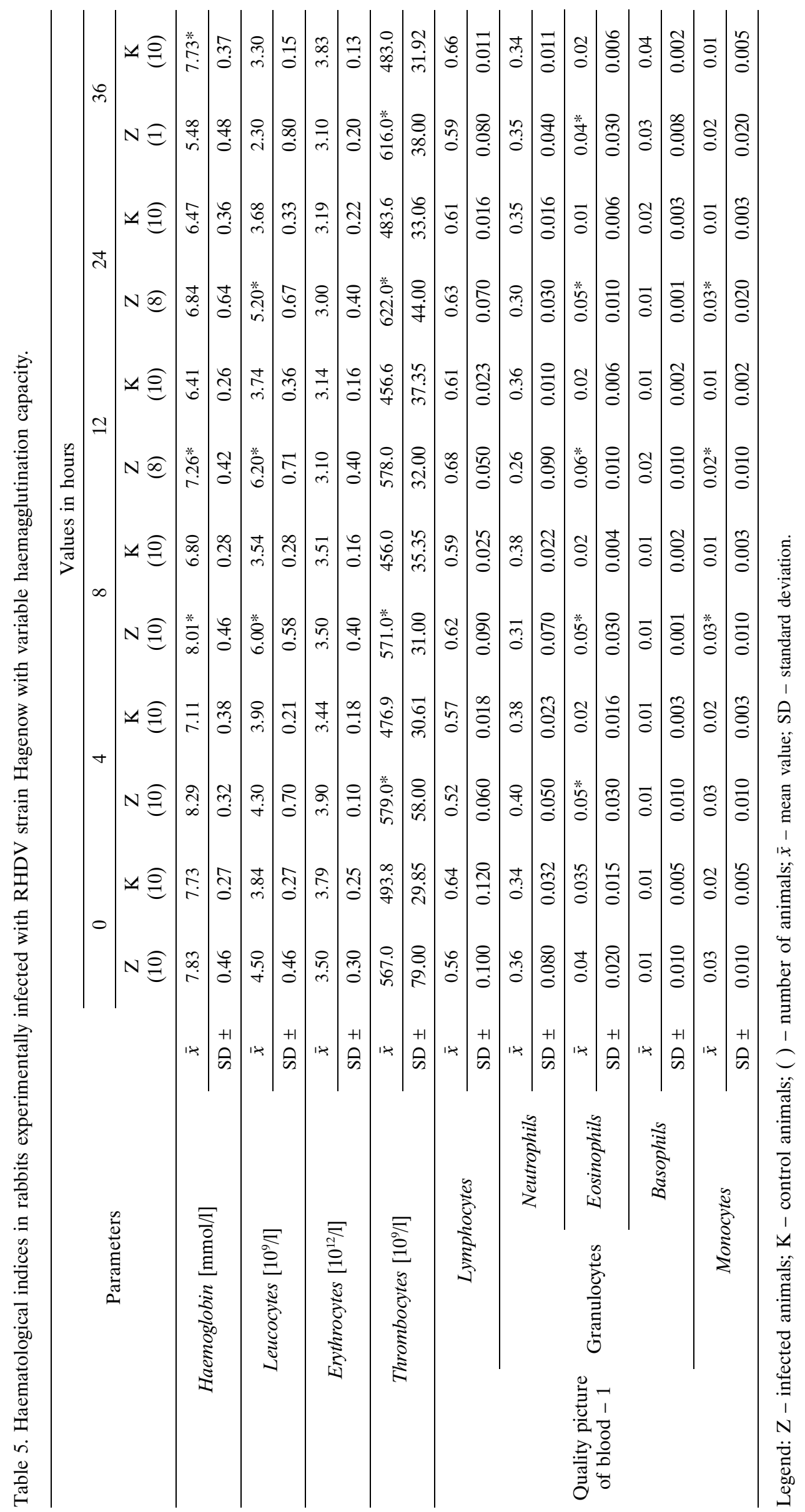


by the Ethics Committee in Szczecin (permission number 11/06).

Rabbits (60 animals) were divided into the following two groups: infected animals - 10 rabbits for each of the three analyzed RHDV strains; 10 animals as controls for each strain. The animals from infected groups were intramuscularly (leg muscles) administered the same doze of RHDV: non-haemagglutinating Frankfurt strain from Germany, and Asturias strain from Spain, and strain with variable haemagglutination capacity Hagenow from Germany, which was prepared according to the previously described procedure (Niedźwiedzka-Rystwej and Deptuła 2010). Such prepared viral antigens were collected to infect animals in these groups, while blood samples were drawn from them and control animals from the auricular marginal vein at hour " 0 ", before administering RHDV and glycerol, and next at 4, 8, 12, 24, and $36 \mathrm{~h}$ of the experiment, until the occurrence of clinical symptoms or first animal deaths (Table 6), according to the recommendation of the Ethics Committee.

Blood analysis involved haemoglobin concentration, quantity of erythrocytes, leukocytes, thrombocytes, and white cell picture (lymphocytes, neutrophil granulocytes, basophil granulocytes, acidophil granulocytes, and monocytes) according to the commonly known and used standards. The assessment of the pathogenicity of the analyzed RHDV strains was carried out by observing clinical symptoms and mortality among the animals, recorded in rabbits observed at $0,4,8,12,24,36$, and $48 \mathrm{~h}$ after their infection with the virus.

The results of haematological tests were subject to the statistical analysis with t-Student test in Statistica 6.0 software as shown in Tables 3-5.

\section{Results}

The changes in HA- Frankfurt and Asturias strains (Tables 3, 4) were only recorded in the number of neutrophils and thrombocytes for HA- Frankfurt strain, while for HA- Asturias strain they were recorded in the volume of thrombocytes and leukocytes. In $\mathrm{HA}+/-$ Hagenow strain, the changes referred to the volume of eosinophils, thrombocytes, leukocytes, monocytes, and haemoglobin concentration.

The analysis of changes in haematological parameters in rabbits infected with HA- Frankfurt strain of RHDV showed (Table 3 ) an increase in the number of neutrophils at 4,8 , and $24 \mathrm{~h}$ p.i. and an increase in thrombocytes at $8 \mathrm{~h}$ p.i. For HA- Asturias strain of RHDV (Table 4), the changes involved a decrease in the quantity of thrombocytes and leukocytes, falling at
12 and $24 \mathrm{~h}$ p.i. for thrombocytes and at $24 \mathrm{~h}$ p.i for leukocytes. The changes in the haematological picture for HA+/- RHDV Hagenow strain (Table 5) involved an increase in the volume of eosinophils $(4,8,12,24$, and $36 \mathrm{~h})$, thrombocytes $(4,8,24$, and $36 \mathrm{~h}$ ), leukocytes $(8,12$, and $24 \mathrm{~h})$, monocytes $(8,12$, and 24 h), and haemoglobin concentration (8 and $12 \mathrm{~h}$ ). For this strain, a decrease in haemoglobin concentration value was also recorded at $36 \mathrm{~h} \mathrm{p.i.}$

When analyzing the clinical picture in rabbits infected with three currently analyzed RHDV strains (Frankfurt, Asturias and Hagenow), it was stated that in HA- strains such as Frankfurt and Asturias, the mortality rate totaled $100 \%$, with the deaths occurring in the period between 36 and $48 \mathrm{~h}$ p.i. for Frankfurt strain and in the period between 24 and $36 \mathrm{~h}$ p.i. for Asturias strain. In HA+/- Hagenow RHDV strain, mortality was $90 \%$ and, similarly as with HA- Frankfurt, deaths occurred between 36 and $48 \mathrm{~h}$ p.i. Clinical symptoms were only observed in one rabbit infected with $\mathrm{HA}+$ - Hagenow strain, between 36 and 48 h p.i., characterized by apathy, difficulties in breathing, lack of response to external stimuli, and nasal fluids. In other animals infected with Hagenow, Frankfurt, and Asturias strains, no clinical symptoms were recorded.

\section{Discussion}

When analyzing the results in haematological parameters in rabbits infected with two non-haemagglutinating Frankfurt and Asturias RHDV strains and one strain with variable haemagglutination capacity Hagenow, it must be stated that the image of changes is slightly different than that previously observed for (HA-) strains, Rainham (Niedźwiedzka 2008, Niedźwiedzka-Rystwej and Deptuła 2009) and BLA, and for $(\mathrm{HA}+/-)$ strain, ŻD (Tokarz-Deptuła 2009). In fact, the changes observed in the present study in the haematological picture for HA- Frankfurt RHDV strain, manifested with the increase in the volume of neutrophils at 4,8 , and 24 h p.i., do not conform to the image of changes obtained for two HAstrains: Rainham and BLA; as in the case of such strains, the changes exclusively referred to the volume of leukocytes (decrease at $12 \mathrm{~h}$ for Rainham, and at 48 $\mathrm{h}$ for BLA) and thrombocytes (decrease at 12, 24, and $36 \mathrm{~h}$ for Rainham, with no changes for BLA) (Niedźwiedzka 2008, Niedźwiedzka-Rystwej and Deptuła 2009, Tokarz-Deptuła 2009). Similarly, an increase in the volume of thrombocytes at $8 \mathrm{~h}$ from infection for the currently analyzed Frankfurt strain does not corroborate the changes recorded for Rainham (Niedźwiedzka 2008, Niedźwiedzka-Rystwej and Deptuła 2009) and BLA (Tokarz-Deptuła 2009), as 
for Rainham, the volume of thrombocytes decreased at 12, 24, and 36 h p.i. (Niedźwiedzka 2008, Niedźwiedzka-Rystwej and Deptuła 2009), while BLA strain showed no changes (Tokarz-Deptuła 2009). Therefore, it must be assumed that image of changes observed in this study in Frankfurt strain, which only manifested an increase in neutrophils and thrombocytes, does not correspond with changes described for previously analyzed Rainham (Niedźwiedzka 2008, Niedźwiedzka-Rystwej and Deptuła 2009) and BLA (Tokarz-Deptuła 2009) strains, for which a decrease was referred in leukocytes (at $12 \mathrm{~h}$ for Rainham, and at $48 \mathrm{~h}$ for BLA) and thrombocytes (at 12, 24, $36 \mathrm{~h}$ for Rainham, with no changes for BLA).

For currently analyzed non-haemagglutinating Asturias RHDV strain, it must be stated that currently recorded decrease in leukocytes at $24 \mathrm{~h}$ p.i. is analogical to that obtained in Rainham strain (Niedźwiedzka 2008, Niedźwiedzka-Rystwej and Deptuła 2009) and is similar to the image of changes recorded at $48 \mathrm{~h}$ p.i. with BLA strain (Tokarz-Deptuła 2009). The decrease in thrombocytes at 12 and $24 \mathrm{~h}$ p.i. with Asturias strain is very similar to the decrease in this factor recorded at 12,24 , and $36 \mathrm{~h}$ for Rainham strain (Niedźwiedzka 2008, Niedźwiedzka-Rystwej and Deptuła 2009), although it differs from the image reported for BLA strain (Tokarz-Deptuła 2009), where no changes in thrombocytes were observed. Therefore, for HA- RHDV strains, it can be assumed that the decreases in the values of haematological factors (leukocytes and thrombocytes) for the currently investigated Asturias strain are similar to the image of changes recorded for previously analyzed Rainham and BLA strains, for which observations included a decrease in leukocytes (decrease at $12 \mathrm{~h}$ for Rainham, and at $48 \mathrm{~h}$ for BLA) and thrombocytes (decrease at 12,24 , and $36 \mathrm{~h}$ for Rainham, with no changes for BLA). For currently analyzed Hagenow strain with variable haemagglutination capacity, the recorded increase in eosinophils at $4,8,12,24$, and 36 $\mathrm{h}$ p.i. does not confirm the results obtained previously for ŻD strain (Tokarz-Deptuła 2009), similar to the differences in the image of monocytes, which increased at 8, 12, $24 \mathrm{~h}$ for Hagenow. The image also differed for Hagenow and $\dot{Z} \mathrm{D}$ in respect of the volume of thrombocytes, as for Hagenow, they increased at $4,8,24$, and 36 h p.i., while no changes were observed for ŻD (Tokarz-Deptuła 2009). Moreover, Hagenow strain does not show changes in the volume of neutrophils, whereas ŻD strain (Tokarz-Deptuła 2009) caused the long-term increase in this factor in the period from 4 to $36 \mathrm{~h}$ p.i. Also, the changes in haemoglobin concentration recorded in the form of an increase at 8 and $12 \mathrm{~h}$ and a decrease at $36 \mathrm{~h}$ for the Hagenow strain do not find the confirmation in the results for $\dot{Z} D$ strain, as no changes in this factor were reported for this strain (Tokarz-Deptuła 2009). A similar image of changes was recorded considering the increase in leukocytes both for the Hagenow strain at 8,12 , and $24 \mathrm{~h}$ and for $\dot{Z} \mathrm{D}$ strain at $8 \mathrm{~h}$, although the latter additionally caused a decrease at $60 \mathrm{~h}$ p.i. (Tokarz-Deptuła 2009). Therefore, to conclude on the present results for $\mathrm{HA}+/$ - Hagenow and $\dot{Z} D$ strains, it can be stated that the changes caused by those strains differ, but regardless of the different image of the changes, these strains show more increases than decreases in the analyzed haematological factors.

When analyzing the changes in the clinical image caused by two currently investigated HA- strains (Frankfurt, Asturias) of RHDV, it must be stated that HA- strains cause $100 \%$ mortality of the animals between 24 and $36 \mathrm{~h}$ (Asturias) and 36 and $48 \mathrm{~h}$ (Frankfurt) p.i. The results confirm the mortality rate obtained for HA- Rainham strain (which also totaled $100 \%$, but deaths occurred at $24 \mathrm{~h}$ p.i.) but slightly differ from the image obtained for HA- BLA strain, where just $60 \%$ mortality was observed, with deaths occurring 60 h p.i. (Niedźwiedzka 2008). Mortality at the level of $90 \%$ between 36 and $48 \mathrm{~h}$ p.i. for the currently investigated HA+/- Hagenow RHDV strain is similar to the results obtained for the previously analyzed strain with variable haemagglutination capacity, ŻD strain, for which $100 \%$ mortality was recorded with deaths at $48 \mathrm{~h}$ p.i.

In conclusion, based on the results obtained, it must be stated that two currently investigated non-haemagglutinating Frankfurt and Asturias strains of RHDV and one strain with variable haemagglutination capacity Hagenow (Tables 3-5) cause different images of the analyzed haematological factors, because Frankfurt strain only causes increases while Asturias exclusively decreases, whereas Hagenow causes both increases and decreases, with the majority of the increases. While assessing the mortality rate of rabbits infected with three currently investigated strains (Frankfurt, Asturias, Hagenow), it must be assumed that they cause high mortality rate because non-haemagglutinating RHDV strains (Frankfurt and Asturias) result in $100 \%$ mortality rate, whereas the investigated Hagenow strain with variable haemagglutination capacity causes $90 \%$ mortality among rabbits, which is analogical to the results obtained for 16 HA+ RHDV strains (Table 2), where mortality was reported at the level of $80-100 \%$, with deaths occurring later from infection (48-60 h) than for currently investigated strains (Frankfurt, Asturias, Hagenow) (24-36 h).

From the present (Tables 3-5) and previous studies (Tables 2, 2a) regarding the assessment of haematological factors for RHDV strains without or with 
variable haemagglutination capacity, it can be stated that these strains, as compared to haemagglutinating strains (Tables 1, 2, 2a), cause fewer changes and are characterized with less clear changes in the haematological picture than that observed for haemagglutinating strains, where more decreases are clearly recorded in haematological parameters. Furthermore, in all HA- and HA+/- RHDV strains analyzed now and previously, the changes principally referred to thrombocytes and leukocytes, although earlier studies on HA- and HA+/- strains also refer to lymphocytes, neutrophils, and haemoglobin concentration, while for haemagglutinating strains, the changes principally referred to lymphocytes. Also, high mortality obtained for presently analyzed $\mathrm{HA}-$ and $\mathrm{HA}+/-$ strains, amounting to $90-100 \%$, is confirmed in the picture of haematological changes, yet it does not confirm the hypothesis popular in clinical sciences (Capucci et al. 1998, Ruvoén-Clouet et al. 2000) that haemagglutinating strains are more pathogenic.

\section{References}

Alexandrov M, Peshev R, Lasarova S, Doumanova L, Tchorbanov A, Bostandjieva R (2009) Heterophil emperipolesis in rabbit haemorrhagic disease. Bul $\mathrm{J}$ Vet Med 12: 43-53.

Annon (1987) Information and training materials of the Laboratory Animals Section, General Assembly of the Association of Agriculture Engineers and Technicians, pp 26-77.

Annon (2010) Regulation of the Minister of Agriculture and Rural Development of 10 March 2006 on detailed conditions for maintenance of laboratory animals in experimental units, breeding units and suppliers http://www.nauka.gov.pl/g2/oryginal/2013-05/59e6734c32 a6abe55da73204137e8138. pdf

Capucci L, Fallacara F, Grazioli S, Lavazza A, Pacciarini ML, Brocchi E (1998) A further step in the evolution of rabbit hemorrhagic disease virus: the appearance of the first consistent antigenic variant. Virus Res 58: 115-126.

Capucci L, Chasey D, Lavazza A, Westcott D (1996) Preliminary characterization of a non-haemagglutinating strain of rabbit haemorrhagic disease virus from the United Kingdom. Zentralbl Veterinarmed B 43: 245-250.

Chen KY (1986) Rabbit plaque. Inf Dis Domestic Anim 3: 53-59.

Chen KY, Zeng DN (1986) Report on 100 cases of rabbit plaque. Inf Dis Domestic Anim 3: 46-52.

Chen KY, Zeng DN, Ning LZ, Yin LY (1987) Changes in blood leukocytes and histology of lymphoid organs in acute of experimentally infected rabbit haemorrhagic disease. Chin J Vet Sci Technol 5: 38-44.

Dalton KP, Nicieza I, Balseiro A, Muguerza MA, Rosell JM, Casais R, Hlvarez HL, Parra F (2012) Variant rabbit hemorrhagic disease virus in young rabbits, Spain. Emerg Infect Dis 18: 2009-2012.

Deptuła W, Kęsy A, Tokarz-Deptuła B, Stosik M (1997) Chosen immunological and haematological parameters in rabbits experimentally infected with RHD (rabbit haemorrhagic disease) virus. Proceedings "Veterinary microbiology yesterday, today and tomorrow", SGGW Warsaw, pp 68-79.

Ferreira PG, Costa-e-Silva A, Monteiro E, Oliveira MJ, Aguas AP (2004) Transient decrease in blood heterophils and sustained liver damage caused by calicivirus infection of young rabbits that are naturally resistant to rabbit haemorrhagic disease. Res Vet Sci 76: 83-94.

Fitzner A (2006) Molecular characteristics of RHD virus with consideration of strains with different phenotype. Habbilitation thesis. National Veterinary Institute Puławy, Poland.

Hukowska-Szematowicz B (2006) Immunological-genetic characteristics of chosen strains of RHD (rabbit haemorrhagic disease) virus. Doctoral thesis, University of Szczecin, Poland.

Kęsy A, Fitzner A, Niedbalski W, Paprocka W, Walkowiak B (1996) A new variant of the viral haemorrhagic disease of rabbits virus. Rev Sci Tech 15: 1029-1035.

Kölbl S, Settele J, Schonbauer M (1990) First occurrence of infectious hemorrhagicdisease of rabbits in Austria. Berl Munch Tierarztl Wschr 103: 261-266.

Kuttin ES, Nowotny N, Nyska A, Schilcher F, Warner $T$ (1991) Rabbit haemorrhagic disease - first outbreak in Israel and review of the literature. Israel $\mathbf{J}$ Vet Med 46: $119-126$.

Le Gall-Recule G, Zwingelstein F, Laurent S, de Boisseson C, Portejoile Y, Rasschaert D (2003) Phylogenetic analysis of rabbit haemorrhagic disease virus in France between 1993 and 2000, and the characterisation of RHDV antigenic variants. Arch Virol 148: 65-81.

Le Gall-Recule G, Lavazza A, Marchandeau S, Bertagnoli S, Zwingelstein F, Cavadini P, Martinelli N, Lombardi G, Guerin JL, Lemaitre E, Decors A, Boucher S, Le Normand B, Capucci L (2013) Emergence of a new lagovirus related to rabbit haemorrhagic disease virus. Vet Res 44: 81.

Marcato PS, Benazzi C, Vecchi G, Della Salda L, Simoni P, Aiello P, Tumino G (1988) Infectious necrotic hepatitis of rabbits. Pathogenic profile of a new haemorrhagic disease. Riv Coniglicoltura 9: 59-63.

Niedźwiedzka P (2008) Immunological profile and apoptosis in rabbits experimentally infected with RHD (rabbit haemorrhagic disease) strains with different biological features. Doctoral thesis, University of Szczecin, Poland.

Niedźwiedzka-Rystwej P, Deptuła W (2009) Haematological pattern in rabbits infected with three strains of RHD virus. Abstr Trudy X Mieżdunarod. Naucznoj-prakticzeskoj konf. mołodych uczenych studentow i aspirantow, Sanct-Petersburg, pp 123-132.

Niedźwiedzka-Rystwej P, Deptuła W (2010) Non-specific immunity in rabbits infected with 10 strains of the rabbit haemorrhagic disease virus with different biological properties. Centr Europ J Biol 5: 613-632.

Niedźwiedzka-Rystwej P, Deptuła W (2011a) White and red blood cells picture in rabbits experimentally infected with RHD virus. Pol J Vet Sci 14: 479-480.

Niedźwiedzka-Rystwej P, Deptuła W (2011b) Indices of white and red blood cells in rabbits experimentally infected with chosen antigenic variants of rabbit haemorrhagic disease virus. Centr Eur J Immunol 36: 145-152. 
Nowotny N, Leidinger J, Fuchs A, Vlasak R, Schwendenwein I, Schilcher F, Loupal G (1993) Rabbit haemorrhagic disease (RHD): Clinical, haematological-chemical, virological-serological and pathomorphological examination on experimentally infected domestic rabbits. Wien Tierarztl Mschr 80, 65-74.

Piekarski J (1994) The immunogical and haematological picture and viral pathomorophogenesis and clinic investigations in rabbits experimentally infected with RHD (rabbit haemorrhagic disease) virus. Doctoral thesis, University of Warmia and Mazury Olsztyn, Poland.

Plassiart G, Guelfi JF, Ganiere JP, Wang B, Andre-Fontaine G, Wyers M (1992) Hematological parameters and visceral lesions relationships in rabbit viral hemorrhagic disease. Zentralbl Veterinarmed B 39: 443-453.

Prieto JM, Martin JM, Espi A, Parra F (2000) A new non-haemagglutinating strain of rabbit haemorrhagic disease virus. In: Lavazza A, Brocchi E (eds) Proceedings of 5th International Congress of the European Society of Veterinary Virology "Veterinary Virology in the New Millenium", Brescia, Italy, pp 204-205.

Ruvoën-Clouet N, Ganiére JP, André-Fontaine G, Blanchard D, Le Pendu J (2000) Binding of rabbit hemorrhagic disease virus to antigens of the $\mathrm{ABH}$ histo-blood group family. J Virol 74: 11950-11954.

Schirrmeier H, Reimann I, Kollner B, Granzow H (1999) Pathogenic, antigenic and molecular properties of rabbit haemorrhagic disease virus (RHDV) isolated from vaccinated rabbits: detection and characterization of antigenic variants. Arch Virol 144: 719-735.

Schlüter H, Schirrmeier H, Bohme R (1990) Status of the diagnosis and control of the hemorrhagic septicemia of rabbits in the DDR. Mh Vet-Med 45, 286-289.

Tian L, Liao J, Li JW, Zhou WR, Zhang XL, Wang HN (2007) Isolation and identification of a non-haemagglutinating strain of rabbit hemorrhagic disease virus from China and sequence analysis for the VP60 gene. Virus Genes 35: 745-752.

Tokarz-Deptuła B (1998) Changes in selected indices of non-specific immunity on rabbits following infection with (viral haemorrhagic disease). Doctoral thesis, National Veterinary Institute Puławy, Poland.

Tokarz-Deptuła B (2009) Immunity phenomena in rabbits infected with the RHD (rabbit haemorrhagic disease) virus. Pol J Env Stud 7: 1-81.

Ueda K, Park JH, Ochiai K, Itakura C (1992) Disseminated intravascular coagulation (DIC) in rabbit haemorrhagic disease. Jpn J Vet Res 40: 133-141.

Xu ZJ, Chen WX (1989) Viral haemorrhagic disease in rabbits: a review. Vet Res Commun 13: 205-212.

Xu FN, Shen WP, Xi QK (1985) Ultrastructural studies on viral haemorrhagic disease in rabbits. Anim Husbandry Vet Med 17: 244-250. 